NASA/TM-2003-212273

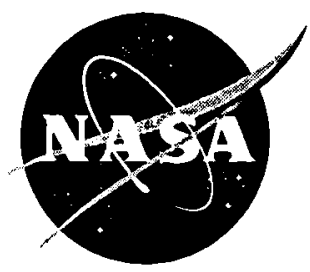

\title{
Development and Demonstration of a Prototype Free Flight Cockpit Display of Traffic Information
}

Walter W. Johnson, Vernol Battiste, Susanne Delzell, Sheila Holland, Sean Belcher, and Kevin Jordan

Ames Research Center, Moffett Field, California

September 2003 
Since its founding, NASA has been dedicated to the advancement of aeronautics and space science. The NASA Scientific and Technical Information (STI) Program Office plays a key part in helping NASA maintain this important role.

The NASA STI Program Office is operated by Langley Research Center, the lead center for NASA's scientific and technical information. The NASA STI Program Office provides access to the NASA STI Database, the largest collection of aeronautical and space science STI in the world. The Program Office is also NASA's institutional mechanism for disseminating the results of its research and development activities. These results are published by NASA in the NASA STI Report Series, which includes the following report types:

- TECHNICAL PUBLICATION. Reports of completed research or a major significant phase of research that present the results of NASA programs and include extensive data or theoretical analysis. Includes compilations of significant scientific and technical data and information deemed to be of continuing reference value. NASA counterpart of peer-reviewed formal professional papers, but having less stringent limitations on manuscript length and extent of graphic presentations.

- TECHNICAL MEMORANDUM. Scientific and technical findings that are preliminary or of specialized interest, e.g., quick release reports, working papers, and bibliographies that contain minimal annotation. Does not contain extensive analysis.

- CONTRACTOR REPORT. Scientific and technical findings by NASA-sponsored contractors and grantees.
- CONFERENCE PUBLICATION. Collected papers from scientific and technical conferences, symposia, seminars, or other meetings sponsored or co-sponsored by NASA.

- SPECIAL PUBLICATION. Scientific, technical, or historical information from NASA programs, projects, and missions, often concerned with subjects having substantial public interest.

- TECHNICAL TRANSLATION. English-language translations of foreign scientific and technical material pertinent to NASA's mission.

Specialized services that complement the STI Program Office's diverse offerings include creating custom thesauri, building customized databases, organizing and publishing research results ... even providing videos.

For more information about the NASA STI Program Office, see the following:

- Access the NASA STI Program Home Page at http://www.sti.nasa.gov

- E-mail your question via the Internet to help@sti.nasa.gov

- Fax your question to the NASA STI Help Desk at (301) 621-0134

- Telephone the NASA STI Help Desk at (301) 621-0390

- Write to:

NASA STI Help Desk

NASA Center for AeroSpace Information

7121 Standard Drive Hanover, MD 21076-1320 
NASA/TM-2003-212273

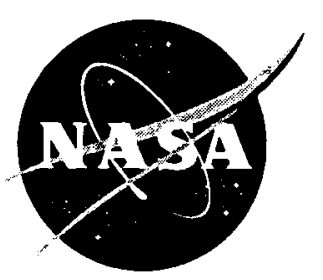

\section{Development and Demonstration of a Prototype Free Flight Cockpit Display of Traffic Information}

Walter W. Johnson, Vernol Battiste

Ames Research Center, Moffett Field, California

Susanne Delzell, Sheila Holland, Sean Belcher, and Kevin Jordan

San Jose State University Foundation, San Jose, California

National Aeronautics and

Space Administration

Ames Research Center

Moffett Field, California 94035

September 2003 
Available from:

NASA Center for AeroSpace Information

7121 Standard Drive

Hanover, MD 21076-1320

$301-621-0390$
National Technical Information Service 5285 Port Royal Road Springfield, VA 22161

703-605-6000

This report is also available in electronic form at http://human-factors.arc.nasa.gov/ihh/cdti/index.html 


\section{Summary}

Two versions of a prototype Free Flight cockpit situational display (Basic and Enhanced) were examined in a simulation at the NASA Ames Research Center. Both displays presented a display of traffic out to a range of $120 \mathrm{NM}$, and an alert when the automation detected a substantial danger of losing separation with another aircraft. The task for the crews was to detect and resolve threats to separation posed by intruder aircraft. An Enhanced version of the display was also examined. It incorporated two additional conflict alerting levels and tools to aid in trajectory prediction and path planning. Ten crews from a major airline participated in the study. Performance analyses and pilot debriefings showed that the Enhanced display was preferred, and that minimal separation between the intruder and the ownship was larger with the Enhanced display. In addition, the additional information on the Enhanced display did not lead crews to engage in more maneuvering. Instead an opposite trend was indicated. Finally, crews using the Enhanced display responded more proactively, tending to resolve alerts earlier.

\section{Introduction}

NASA Ames Research Center is investigating displays for cockpit situational awareness, with the hope of assisting the implementation of Free Flight. This work is in response to the RTCA Task Force 3 Report on Free Flight Implementation', which identified cockpit situational awareness displays as a key component of the next generation air traffic management (ATM) system. This report states that "The architecture and technology on which the emerging ATM system is based makes increasingly heavy use of new displays that provide flight crews with real time situational awareness." Therefore, the RTCA report recommends the immediate initiation of "the development of standards for a cockpit situational awareness display of traffic information." Determining these standards requires a detailed human factors evaluation, where the nature and format of the displayed information are examined.

While the exact functions supported by a cockpit situational display (CSD) depend upon the operational concept that underlies Free Flight, a degree of crew responsibility for selfseparation resides in almost all proposed Free Flight concepts (see the RTCA Task Force 3 Report ${ }^{1}$ for a discussion of Free Flight evolution). Early in the development of Free Flight, conflict calculations, conflict resolutions, and flight replanning will probably be done on the ground by the ATC, with alerts and instructions issued to aircraft by the ATC (in cooperation with the airline operation center, AOC).

However, the role of the flight crew will be significantly enhanced, even in this early system. Their most likely role, which the CSD must support, will be: 1) to monitor for safe and effective flight: and 2) to make requests of the ATC consistent with these criteria. In the safety case the CSD may allow the crew to view potential losses of separation. Thus, in active coordination with the ATC, the pilots could use the CSD as an aid in detecting and resolving potentially dangerous situations. In the effectiveness case the CSD may allow the crew to optimize other criteria by requesting potentially advantageous re-routings. Later in the development of Free Flight, telecommunications and cockpit automation/display advances may make it possible to give more discretionary authority to the cockpit crew. In this case the role of the ATC would be 1) to provide safe operating constraints upon flight paths; and 2) to monitor safe flight and intervene if a dangerous situation occurs. In between these two points, and within different flight regimes (e.g., enroute and terminal area) differing mixes of authority and responsibility may be imagined. 
Almost any envisaged CSD must meet certain design goals. First, the CSD should provide the crew with sufficient predictive information so they can respond to potential conflicts in a proactive, and not reactive, manner. That is, a CSD should give a crew the information and tools that allow them to monitor and evaluate developing conflict situations, and to select candidate maneuvers well before such decisions become critical. Therefore, the display should incorporate a system that gives good advance information about possible conflicts (e.g., an alerting system) and also provides the crew with means for resolving conflicts (e.g., a path planning tool).

However, while providing a display that incorporates good advanced conflict detection may be an important, it is not a sufficient, criterion for a good CSD. The crew of an aircraft may know about goals and concerns that are unavailable to the automation, and therefore be sensitive to aspects of the evolving traffic pattern which escape the automation. For example, crews may get information in flight briefings that is unavailable to automation, or get updated information from voice communications (e.g., party line information about weather and other problems). Such information may be about changes in intended paths of other aircraft (revised flight plan), or about factors that can be reliably expected to influence these flight plans (e.g., reports of turbulence at some altitude). In addition, crews learn from experience. In order to evaluate the impact of these factors the crews need the ability to project the present situation into the future, and not just rely upon the automation to inform them of potential problems (conflict predictions) and the set of possible resolutions (resolution advisories). How far into the future, and what subset of traffic the crew must be able to monitor/extrapolate is a subject for debate and investigation.

Finally, to effectively provide the crew with this information, display design must be highly concerned with format issues. Simply placing the information on a display is not enough. The display must not be cluttered, it must be easy to monitor and remember, and it must never lead to confusion. In addition to these objectives, this must be accomplished in a manner that keeps workload low (the crew must not be heads-down and "flying the display").

The work reported in this paper focused on the development and examination of an initial CSD prototype for commercial enroute airspace operations along with its preliminary evaluation in a high fidelity Boeing 747-400 flight simulator. This work took place within the context of a larger Free Flight Demonstration Simulation. The goals and results of that larger effort will not be reported here. Instead, this report will focus on the design, and initial evaluation, of the prototype CSD.

\section{Design Goals}

The first part of this report documents the function, structure, and rationale for our prototype CSD. The design effort focused on meeting three design goals. The first design goal was to provide a basic display that captured the fundamental elements of the present traffic situation, i.e., traffic location, altitude, heading, climb/descent, and identity, while attempting to manage clutter. Direct display of traffic speed was not used in this first prototype since the use of speed almost always involves extrapolation, and extrapolation by humans is quite error prone ${ }^{2}$. Therefore, speed information was handled by prediction/extrapolation tools made available to the crews.

The second design goal was to develop an alerting system that could provide crews with advanced information about potential conflicts. This would allow crews to begin planning for the resolution earlier, to resolve conflicts earlier, or both. This design goal is controversial however. On the one hand, early predictions could lead to unnecessary maneuvering as crews respond earlier in an 
attempt to avoid low probability potential encounters. On the other hand, early maneuvering can be more efficient than late maneuvering with the crew being able to select more gradual maneuvers when given more time and distance to the potential conflict. Furthermore, early predictions can remove both the surprise and heightened workload that accompany alerts to imminent conflicts.

The third design goal was to provide tools that allowed the crews to more effectively predict the evolution of the present traffic pattern, and to predict the consequences of potential maneuvers that they might make. Thus we were attempting to provide tools to give the crew 4-D situational awareness based upon both the present situation and upon potential situations.

Many design issues were not addressed in this early design prototype. For example, we did not attempt to include tools that might directly provide crews with resolution advisories based on measures of fuel or time efficiency. Instead, we looked at their abilities to resolve conflicts by determining their own maneuvers. Also, since problems posed by Free Flight concepts are most tractable in the enroute sectors (due to the congestion in the terminal area), we have initially concerned ourselves with designing a display that would be useful in the enroute environment. For this reason this initial prototype is called the Airborne Management of Enroute Separation (AMES) display.

\section{Evaluation Goals}

The second part of this report describes the simulation evaluation of the prototype CSD. This simulation was designed to surface issues and provide future research direction on CSD development and evaluation - it was not designed to allow definitive conclusions about the overall adequacy of the prototype CSD, nor about the efficacy of Free Flight using these displays.

The simulation evaluation focused on two related goals. The first goal was to determine if our general approach to CSD design was on the right track. Our approach to this was to compare two versions of the CSD within a highly idealized flight environment, using objective data from a set of candidate dependent measures, and subjective data taken from crew debriefings. One version of the CSD contained a minimum of functionality (e.g., traffic depiction and a simple conflict alert) while the second contained additional enhancements that met the design goals described in the previous section. This simulation was designed to examine the global display design, and not to not gather detailed performance data about the value of the individual elements within the CSD.

The second goal of the simulation was to examine the sensitivity of some candidate performance measures. Selection of dependent measures in realistic or quasirealistic flight simulations is difficult if the goal is to provide a measure of safety. For purposes of maintaining legal separation,

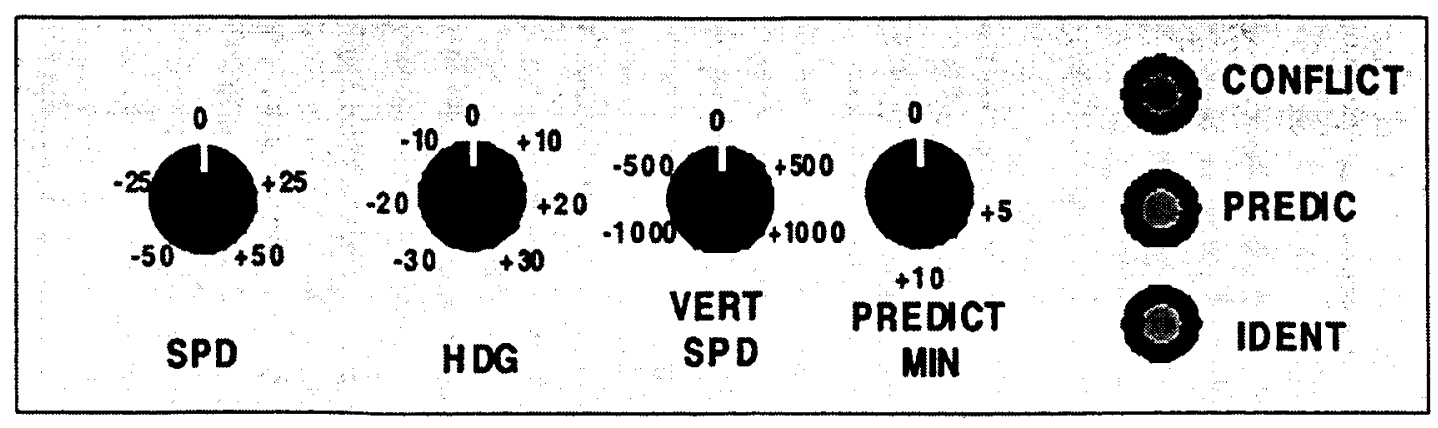

Figure 1. Control panel. 
safety has been defined as maintaining specified separation criteria. On the other hand, a more general definition of safety (or its inverse, threat) is almost certainly a much more multidimensional concept, especially in a Free Flight environment. For example, the RTCA has expanded the area of concern to a much larger (although as yet undefined) alert zone based on tobe-determined criteria ${ }^{1}$. Furthermore, the sensitivity of legal separation as a dependent measure is very low in scenarios that do not immediately place an aircraft into a critical situation. Therefore, since this safety concept has not yet been defined, and since the legal measure of safety is of low sensitivity, candidate dependent measures were selected on the basis of their potential to illuminate the relative impact of the CSD on certain types of performance (e.g., degree of proactive response) and not on safety per se. These dependent measures will be described and discussed in the Methods section.

\section{AMES Traffic Display Description}

The AMES display is composed of three fundamental parts. First there is the symbology associated with the basic traffic display. Second there is the symbology associated with the conflict alerting logic. Third there is the symbology associated with the display tools that help the crew examine potential future traffic scenarios.

\section{Basic Traffic Display}

The basic traffic display was built upon functionalities present in the Map Mode of the Visual Navigation Display present in the Boeing 747-400. This display is shown in Figure 1 in an expanded forward view with a 160 mile range, but was also available to the crews in a full $\left(360^{\circ}\right)$ compass mode, and with display ranges going from $20 \mathrm{NM}$ to $640 \mathrm{NM}$. However, although the cockpit display could be set to longer ranges, the effective simulated range of the display was limited to the 120 NM range that the RTCA has suggested for the proposed Automated Dependent Surveillance

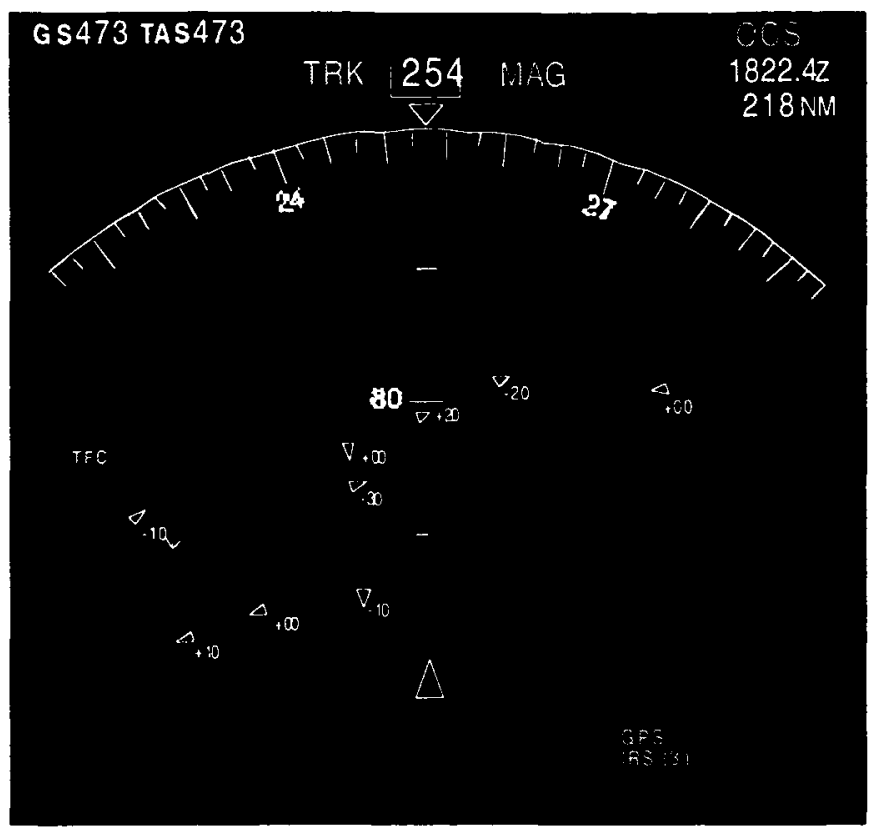

Figure 2. Basic traffic display.

Broadcast system (ADS-B) system1. The display depicts the traffic as elongated open white triangles showing aircraft headings and associated data tags. All data tags contain relative altitudes ( $f(x 100$ ), and also contain up and down arrows $(\uparrow \downarrow)$ that indicate when an aircraft is climbing or descending. The data tags may also contain aircraft ID if a pilot wishes. The pilot could toggle the IDs for all aircraft on and off using a button (IDENT) on an additional control panel (see Figure 2). Due to programming constraints, it was not possible to toggle on and off individual IDs in this simulation, although this was known to be a potentially valuable display decluttering option. 


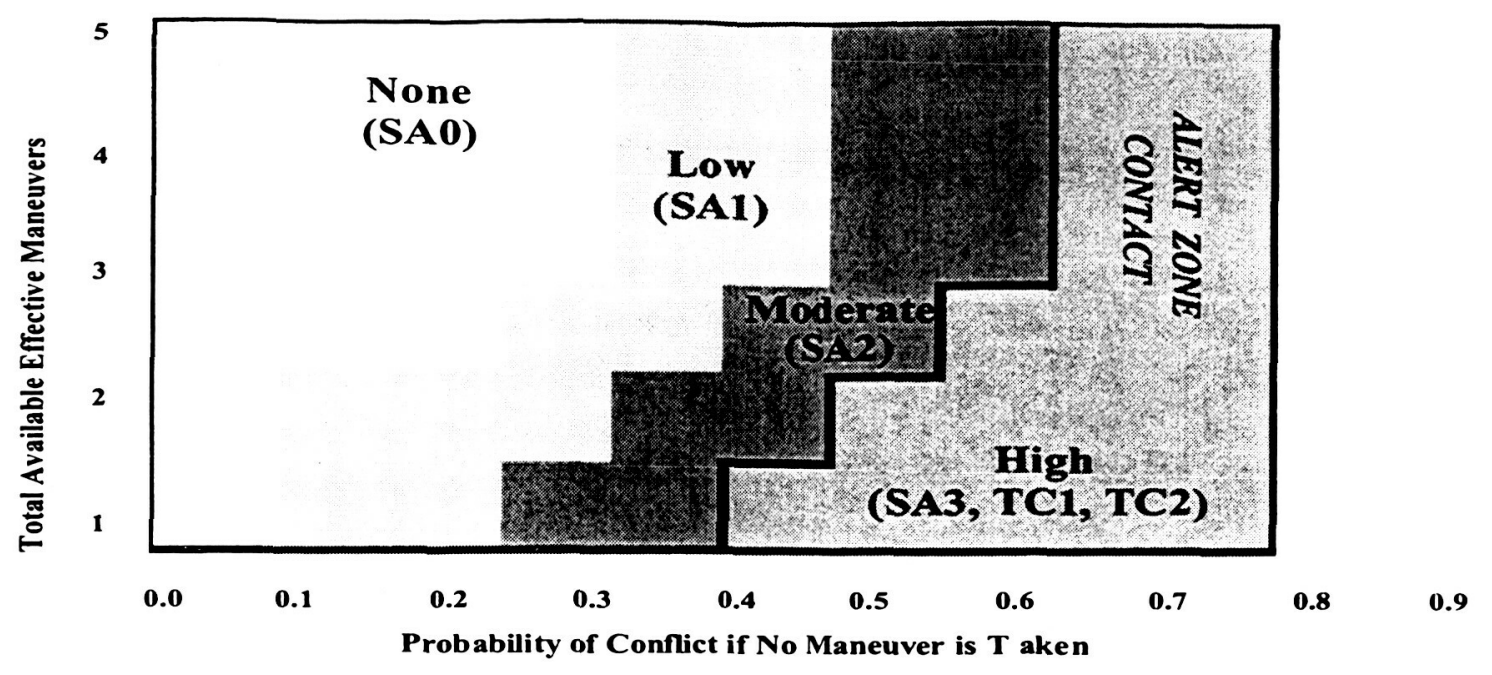

Figure 3. Threat level as a function of conflict probability and number of available effective maneuvers.

\section{Conflict Alerting}

An evolving threat concept guided our design of the conflict alerting displays. This followed from our desire to provide the crew with as much forewarning as possible about a potential threat. To accomplish this, we took advantage of the fact that we can heighten attention without necessarily sounding an alarm. When an aircraft exceeds some minimal threat potential it can be highlighted. This has several advantages. First, at greater distances much smaller maneuvers can lead to effective avoidance. Second, at greater distances the crew has time to monitor and plan for eventual maneuvers if they become necessary. This removes time pressure and the need for an emergency response by the crew. By providing multiple stages the crew can monitor threat evolution and decide when and if it is necessary to take action.

The threat status of all aircraft within the 120 NM ADS-B surveillance range are mapped into six threat levels - four Free Flight situational awareness (SA) levels, and two TCAS (TC) levels. These threat levels are computed by a Free Flight conflict algorithm developed by Yang and Kuchar at MIT ${ }^{3}$ and by the TCAS II algorithm. The Free Flight threat levels are related to potential, or occurring, 'alert zone' contacts. The alert zone concept, originally proposed in the RTCA Task Force 3 Report ${ }^{1}$, defined an alert zone in terms of a temporal and/or spatial safety envelope surrounding an aircraft. Thus, when an aircraft penetrated the alert zone of another aircraft, this 'alert zone contact' signified a significant potential for loss of some minimal separation between those aircraft. However, where the original RTCA alert zone concept is based on temporal and/or spatial envelopes around an aircraft, the alert zone concept used in Yang's and Kuchar's algorithm was based on two different threat components, although these are still strongly affected by temporal and spatial proximity.

The two threat components used by Yang and Kuchar are shown in Figure 3. The threat component defined as "probability of conflict if no maneuver is taken" corresponded to the probability of a simultaneous loss of 5 mile horizontal separation and $1000 \mathrm{ft}$ vertical separation between aircraft if no avoidance maneuver is taken. Estimates of conflict probability are taken from the output of an airborne conflict alerting logic produced by Yang and Kuchar. This logic produces estimates of the probability of conflict (loss of separation) between one's own and other aircraft (traffic). This logic uses probabilistic extrapolations of the present trajectory of Ownship and traffic to generate a probabilistic 
distribution of future Ownship and traffic locations. For Ownship the random component modeled in the extrapolation is assumed to come solely from random physical disturbances, primarily wind fluctuations. The distribution of this random component is assumed to be normal and to generate trackaligned fluctuation in speed $(\sigma=15 \mathrm{kt})$, and fluctuation in cross-track error ( $\sigma=1 \mathrm{NM})$. These specific parameters were estimated from data obtained empirically from traffic by Paielli and Erzberger ${ }^{4}$. Extrapolations of traffic and Intruder positions assumed these same random processes, but also included another two additional components to capture deliberate (intent driven) changes in altitude and heading. In these components the probabilities of a turn or an altitude change were modeled as Poisson processes, with mean rates of 4 turns/hour and 4 altitude changes/hour. When they occurred, the magnitudes of these changes were randomly drawn from distributions in which 1) heading changes between $5^{\circ}$ and $20^{\circ}$ were equally likely, and heading changes less than $5^{\circ}$ were less likely; and 2) altitude changes between 0 and $10,000 \mathrm{ft}$ were equally likely.

The threat component defined as Total Available Maneuvers corresponds to the number of maneuvers (climb/descend, turn left, turn right, speed up, slow down) that will bring the conflict probability below 0.05 . In this study 5 maneuvers were defined together with maximum maneuver sizes. Two of these maneuvers were standard rate turns (left or right), with a maximum 30 degree tum being allowed. Another two maneuvers corresponded to increasing or decreasing true airspeed by up to 50 knots 2 . A climb or descent at $1000 \mathrm{ft} / \mathrm{min}$ counted as the fifth maneuver. Climbs and descents were combined into a single maneuver category since conflicts could always be resolved if either or these were initiated at least one

2 No simulated winds were present so true airspeed was equal to ground speed. Also, speed increases of up to 50 knots were allowed, but not always possible for a particular initial speed and flight level. minute ahead of time. Thus resolutions using climbs and descents remained available much longer than did resolutions involving speed or heading maneuvers. Thus it was decided, in effect, to decrease the weighting on the altitude maneuver (since it did not reflect maneuvering constraints until very late) by collapsing both climbs and descents into a single maneuver category.

All maneuvers was assumed to be preceded by probabilistic delay with a mean of 1 minute and a $95 \%$ probability of being less than 2 minutes, and with the maneuver being instantaneously effective when it did occur. This was done to model the crew flight response latency to a conflict, and thus give the crew sufficient time to coordinate with other aircraft and/or the ATC.

No vehicle dynamics were incorporated in the conflict alerting software, and instantaneous changes in heading, altitude rate, and speed (after a delay of $1 \mathrm{~min}$ ) were assumed. However, this delay plus immediate change was probably a close approximation for turns and altitude changes since most turns and altitude rate changes could be made within 10 to 20 seconds. On the other hand, this cannot be said for the speed changes since it takes fairly longer intervals to change speed by 50 knots (and sometimes it cannot be done at all).

Prior to, or at the time of an alert zone contact, the crew was expected to evaluate and resolve it by deciding among three actions. These actions are 1) no action, 2) maneuvering or negotiating a maneuver with the other aircraft, or 3) by handing off the problem to the ATC who will then direct the required maneuver. 
Table 1. Threat Level Description, Alert Status, and Symbology.

\begin{tabular}{|l|l|l|l|l|}
\hline $\begin{array}{l}\text { THREA T } \\
\text { ID }\end{array}$ & $\begin{array}{l}\text { SAE } \\
\text { Alert } \\
\text { Category }\end{array}$ & $\begin{array}{l}\text { ALERT } \\
\text { STATUS }\end{array}$ & $\begin{array}{l}\text { THREAT } \\
\text { LEVEL }\end{array}$ & SYMBOLOGY \\
\hline $\mathrm{SA}_{0}$ & 0 & No Alert & No Threat & White Open Triangle \\
\hline $\mathrm{SA}_{1}$ & 0 & No Alert & Low Threat & Blue Open Triangle \\
\hline $\mathrm{SA}_{2}$ & 0 & No Alert & Mod Threat & Blue Filled Triangle \\
\hline $\mathrm{SA}_{3}$ & 1 & $\begin{array}{l}\text { Alert Zone } \\
\text { Contact }\end{array}$ & High Threat & $\begin{array}{l}\text { Blue Filled Triangle, Solid Ownship } \\
\text { Route line, Solid Intruder route } \\
\text { line, and solid outlined Airspace } \\
\text { boundaries, Blue ALERT message } \\
\text { with estimated time to closest } \\
\text { approach (CTA) }\end{array}$ \\
\hline $\mathrm{TC}_{1}$ & 2 & $\begin{array}{l}\text { TCAS } \\
\text { Traffic } \\
\text { Advisory }\end{array}$ & $\begin{array}{l}\text { Very High } \\
\text { Threat }\end{array}$ & $\begin{array}{l}\text { Amber filled Diamond, Blue } \\
\text { ALERT message with estimated } \\
\text { time to closest approach (CTA) }\end{array}$ \\
\hline $\mathrm{TC}_{2}$ & 3 & $\begin{array}{l}\text { TCAS } \\
\text { Resolution } \\
\text { Advisory }\end{array}$ & $\begin{array}{l}\text { Very High } \\
\text { Threat }\end{array}$ & $\begin{array}{l}\text { Red filled Diamond, Blue ALERT } \\
\text { message with estimated time to } \\
\text { closest approach (CTA) }\end{array}$ \\
\hline
\end{tabular}

The final two threat levels are taken from the TCAS II algorithm (Traffic Alert and Resolution Advisory). This algorithm generates four threat levels, but only the two most serious levels were used in the present implementation. The threat levels corresponding to the two least serious TCAS II advisories were not used in the display, since the functions of these SA levels were effectively provided by the Free Flight SA levels. However, the two most serious TCAS II alerts were included since they signaled progressions beyond an $\mathrm{SA}_{3}$, and they provided resolution information that was not included in the Free Flight SA levels.

Each Free Flight and TCAS threat level had its own unique associated display symbology (see Table 1 and Figures 1, 4-8). The symbologies for the Free Flight levels were selected so that they would not conflict (be similar in color or shape) with the symbologies already in use within the 747 navigation display. The symbologies for the final two levels were the same as those used for the two highest TCAS II alert levels.
Table 1 also shows how these threat levels, and their associated symbologies and aural alerts, can be mapped directly into the alert categories specified in the SAE recommended practice for flight deck alerting systems ${ }^{5}$ shown in Table 2. The first three Free Flight Situational Awareness (SA) threat levels $\left(S A_{\omega}\right.$ $S A_{1}, S A_{2}$ ) represent no threat to moderate threat and are intended to be simply informative. As the threat of any aircraft on the display increases across these levels its associated symbolic depiction changes as indicated in Figures 1, 4, and 5 and Table 1.

The next threat level, $\mathrm{SA}_{3}$, is associated with the onset of an alert zone contact (Figure 6). An $\mathrm{SA}_{3}$ level is assumed to reflect a significant threat to which the crew must devote their attention and to which they may have to respond. Consistent with this need to bring an $\mathrm{SA}_{3}$ to the crew's attention, when an alert zone contact first occurs only the aircraft positions and altitudes remained on the display with the alert symbology. In some cases this required the removal of symbology associated with the display tools (described below) as well as the removal of all non-intruder aircraft IDs. The 
Table 2. SAE Alerting Categories.

\begin{tabular}{|c|l|l|l|l|}
\hline $\begin{array}{l}\text { SAE } \\
\text { LEVEL }\end{array}$ & CONDITION & CRITERIA & \multicolumn{2}{|l|}{$\begin{array}{l}\text { ALERTING SYSTEM } \\
\text { CHARACTERISTICS }\end{array}$} \\
\hline 3 & Emergency & $\begin{array}{l}\text { Conditions which require } \\
\text { immediate corrective or } \\
\text { compensatory action by } \\
\text { the crew }\end{array}$ & Required & Red \\
\hline 2 & Abnormal & $\begin{array}{l}\text { Conditions which require } \\
\text { immediate crew } \\
\text { awareness and } \\
\text { subsequent corrective or } \\
\text { compensatory crew } \\
\text { action }\end{array}$ & Required & Amber \\
\hline 1 & Advisory & $\begin{array}{l}\text { Conditions which require } \\
\text { crew awareness and may } \\
\text { require crew action }\end{array}$ & Permitted & Optional (not red) \\
\hline 0 & Information & $\begin{array}{l}\text { Conditions which require } \\
\text { flight deck indication, } \\
\text { but not necessarily as } \\
\text { part of an alerting system }\end{array}$ & None & Green, blue or white \\
\hline
\end{tabular}

$\mathrm{SA}_{3}$ symbology was composed of the $\mathrm{SA}_{2}$ symbology plus collision route lines extending from Ownship and the aircraft posing the threat. These route lines terminated with 2.5 NM radii circles at the estimated point of closest approach. Circles with this radius were used since a visual overlap to two such circles would indicate a violation of the $5 \mathrm{NM}$ protected zone surrounding each aircraft. The word "ALERT", was presented in large blue letters at the bottom right of the display along with the estimated time (in minutes and seconds) to closest approach (CTA), and remained on until the threat levels dropped below $\mathrm{SA}_{3}$. An audible advisory ("Alert Zone Transgression") was presented simultaneously with the display change. If, at this time, the crew wished to return any of the eliminated symbology for the non-involved traffic, they could do so.

The final two threat levels $\left(T C_{l}, T C_{2}\right)$ are associated with the two highest TCAS threat levels and use the standard TCAS symbologies and audible warnings. In addition the ALERT message remains on.

\section{Display Tools}

\section{Predictor Tool}

Pilots face a significant problem when called upon to extrapolate a present traffic situation into the future since there is often considerable variability in the human prediction of motion ${ }^{2}$. Therefore, without the type of training and experience given to air traffic controllers, most pilots will require some form of automated aiding. Although the alerting logic relies upon computational extrapolations to assess threat, it only makes this assessment available to the crew in terms of the assigned threat levels. Thus, this logic alone does not provide the crew with a picture of how the traffic situation will evolve over time. Instead it leaves the crew completely dependent on the basic display plus alerting logic for both threat evaluation (in detection and resolution) and for future situational awareness. In other words, this logic leaves a gap between the detection of an aircraft that may pose a problem at some specific time and place in the 


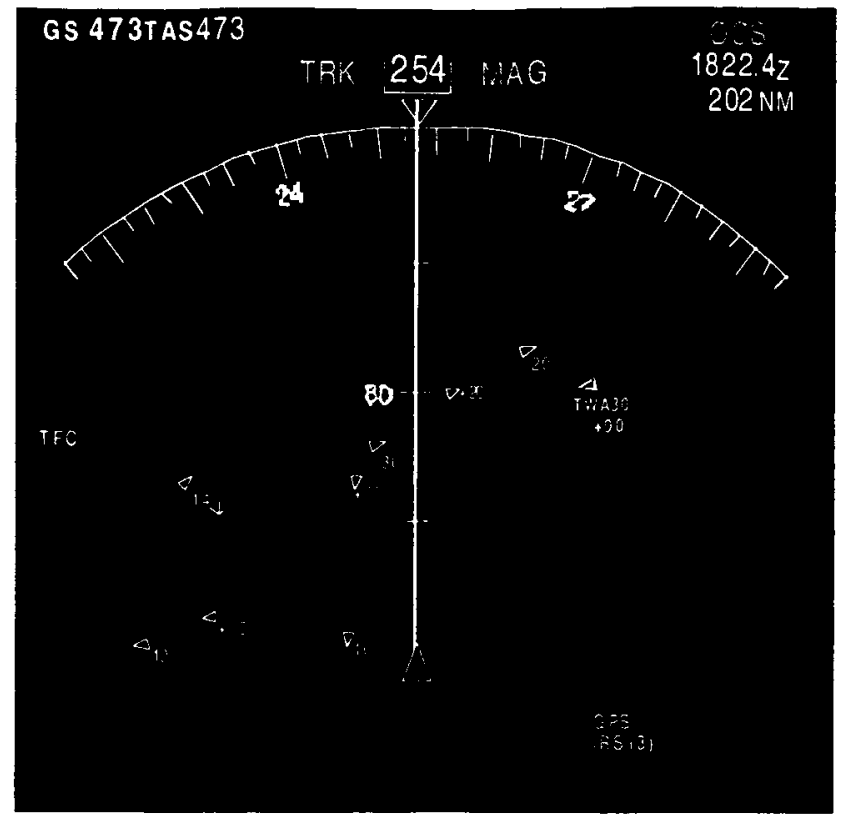

Figure 4. Situational awareness level $1\left(\mathrm{SA}_{1}\right)$. Blue is depicted as bold white.

future (which the logic provides), and the understanding of the evolving traffic pattern, including other non-alerted aircraft, that is needed for resolutions (which the logic does not provide). The predictor tool is designed to fill in this gap by allowing a pilot to extrapolate the positions of all aircraft on the display. A pilot accomplishes this by first selecting the predictor tool using the "PREDIC" button on the control panel (Figure 2). Then a pilot may choose to display predicted route lines by setting the temporal predictor to a value between 0 and 10 minutes (see dotted line in Figure 7). This prediction is based simply on the assumption that the aircraft will continue along their present track, at their present speed, for the specified period of time. No turn rate information is included or assumed in this display. The predicted route lines are depicted as solid lines with the same color as the associated aircraft symbol. These lines project from the front of Ownship and from the front of all other aircraft. They extend out distances corresponding to the specified number of minutes. Centered on the end of each route line is a $2.5 \mathrm{NM}$ radius circle depicting the projected location of the protected airspace region at the end of the prediction interval (Figure 7). If crews ensure no overlap in

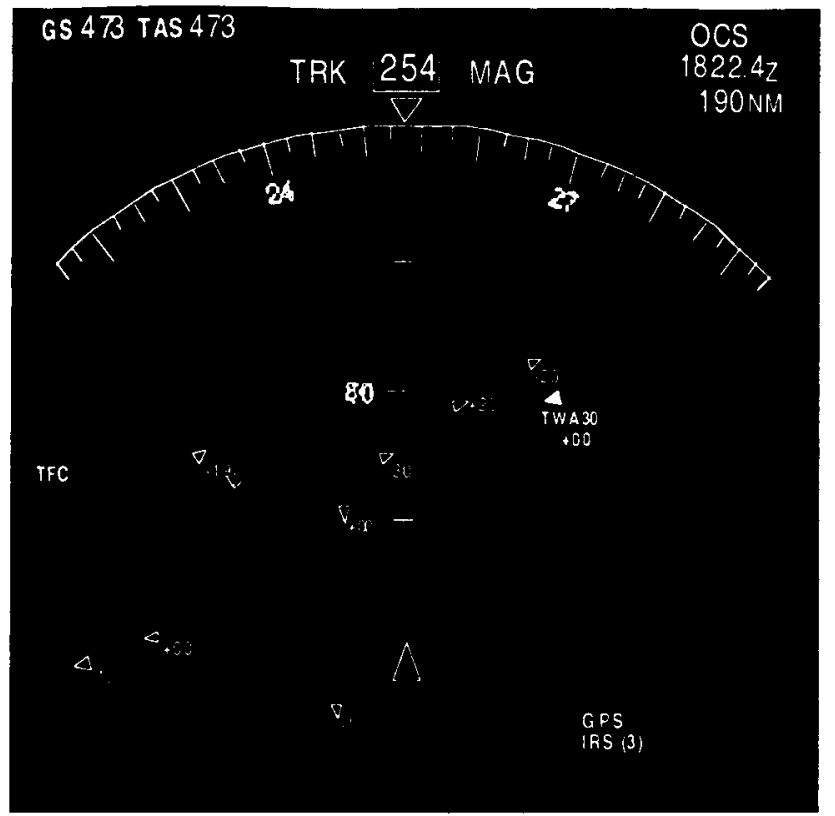

Figure 5. Situational awareness level $2\left(\mathrm{SA}_{2}\right)$. Blue is depicted as bold white.

protected regions then a $5 \mathrm{NM}$ separation is assured.

\section{Route Assessment Tool}

In a system where the crew may be responsible for selecting new routes, the crew needs to be able to evaluate the safety of proposed course modifications. The Route Assessment Tool (RAT) helps the crew to do this by providing the means to generate and test potential changes to vertical speed, path speed, and heading. The RAT is enabled using the CONFLICT selection button on the control panel (Figure 2) and allows a pilot to probe for clear paths. While in the RAT Mode a pilot may examine various heading ( $\pm 30 \mathrm{deg}$ ), speed ( \pm 50 knots) and altitude rate $( \pm 1000$ $\mathrm{ft} / \mathrm{m}$ ) changes using the dials on the control panel.

When the RAT is enabled a white dashed "what-if" route line is displayed in addition to the present route line, and the word "RAT" appears in large white letters at the bottom right of the display together with indications of the present values of the RAT speed and vertical speed settings (Figures 8 and 9). The "what-if" route line extends out for a projected 10 minutes (the same as that used for "what-if" conflict detection while in the 


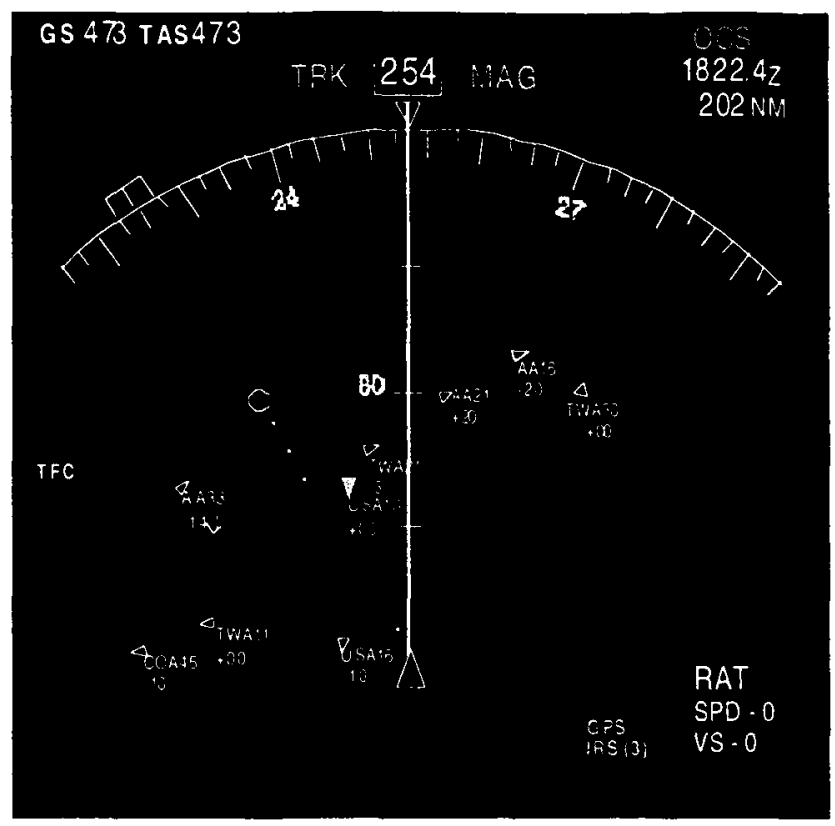

Figure 6. Using the route assessment tool (RAT) and showing a new $\mathrm{SA}_{2}$ conflict along a potential path. Blue is depicted as bold white.

RAT Mode) and, in combination with the conflict detection logic, is used to assess potential conflicts along this proposed path. When various SA Levels are triggered by the RAT the same symbology used for standard conflict alerting is employed with the following exceptions. For a RAT induced $\mathrm{SA}_{3}$ (Alert zone contact) no audible alert is sounded, no ALERT message is displayed (unless there is already an ALERT in progress), and the display will not be cleared of any aircraft IDs or of any RAT or Predictor Tool symbology.

If a true $\mathrm{SA}_{3}$ alert occurs while a pilot is using the RAT, the RAT is disenabled and a decluttered alert depiction is displayed (see below).

The RAT was designed to assume that Ownship maneuvers would become instantaneously effective 1 minute in the future. This is instead of the probabilistic function with a mean of 1 minute used for the standard alerting logic described earlier. For example, when at time $\underline{t}$, a pilot examined the consequences of a 10 degree turn, the RAT would approximate this maneuver as an instantaneous 10 degree turn at time $\underline{t+1}$. Furthermore, due to limitations in the RAT

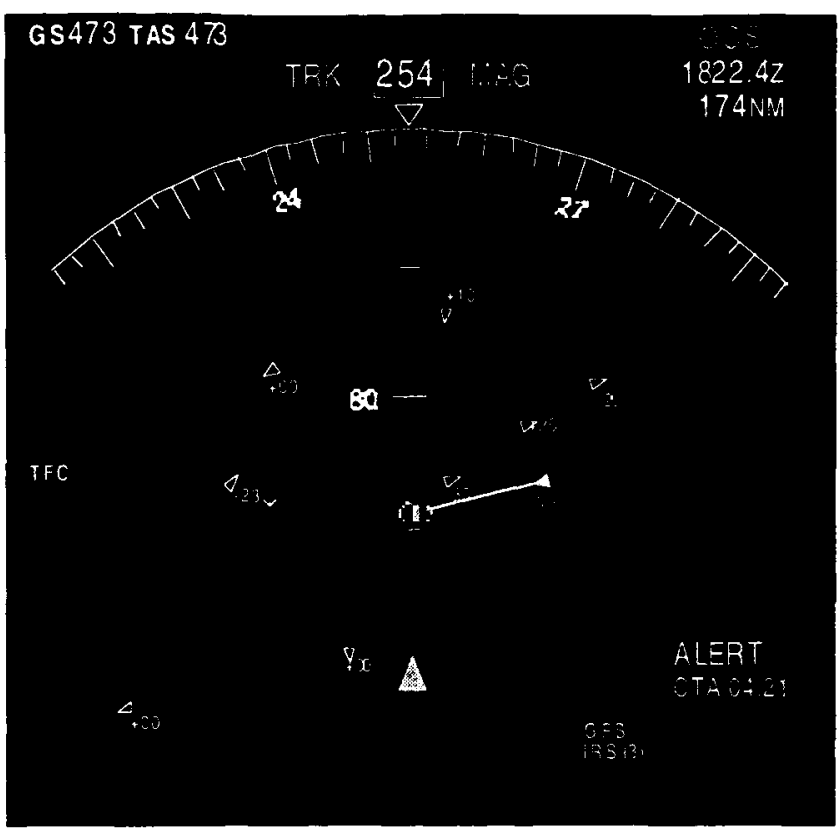

Figure 7. Situational awareness level $3\left(\mathrm{SA}_{3}\right.$ or Alert Zone Contact). Blue is depicted as bold white.

software, only RAT advisories from this time $(\underline{t+1})$ forward were displayed. Thus the RAT did not generate SA levels and advisories for the initial first minute of the prediction.

\section{Simulation Evaluation of AMES Display}

A simulation examining these display concepts during en route flight was conducted using the Boeing 747-400 Level D flight simulator located at the NASA Ames Research Center ${ }^{6}$.

The purpose of the simulation was to provide initial data on the ability of crews to conduct en route Free Flight and resolve conflicts from the flight deck. In most ways the simulation reflected optimistic assumptions about the quality of surveillance information, alerting systems, and the ease of air-to-air communications. The difficulty of the flight scenarios was also minimized in the simulation. Specifically, the simulation incorporated the following features:

1. Error free surveillance information (traffic positions, velocities, headings, vertical speeds, and altitudes).

2. No weather, no winds.

3. No extraneous heading or speed maneuvering by traffic aircraft (traffic 


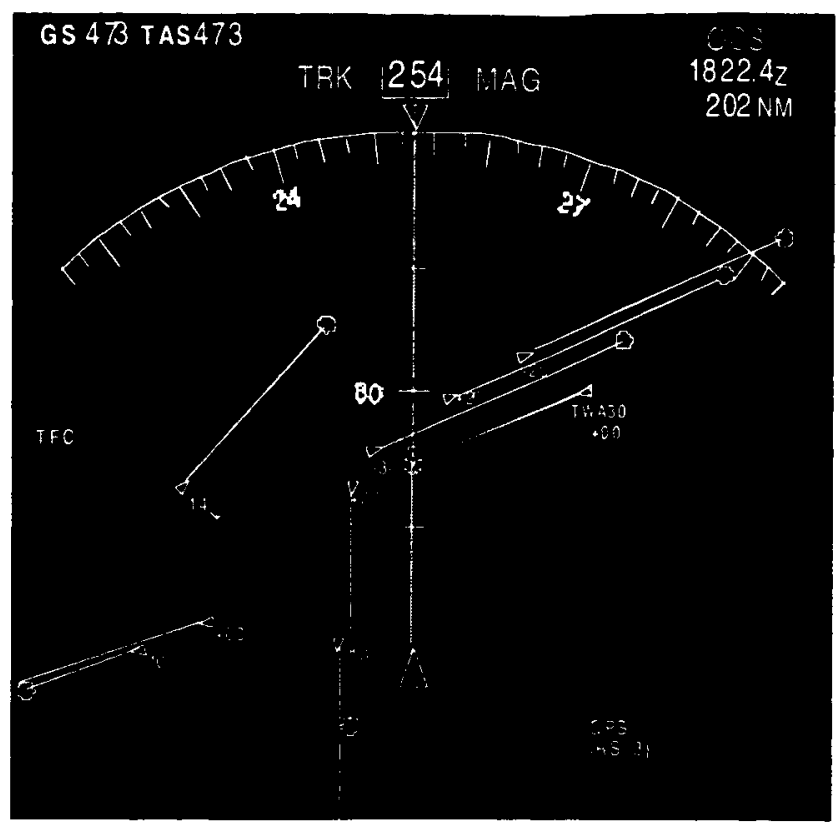

Figure 8. Situational awareness level 1 with predictor tool set at 6 minutes. Blue is depicted as bold white.

aircraft, with the exception of specific Intruder aircraft used to create threats, never changed direction, or speed).

4. Traffic density was moderate to low (never more than 10 aircraft within surveillance range).

5. No linkage between SA levels and probability of a conflict with Intruder.

Thus there were no false alarms. So when any SA or alert level occurred, the involved aircraft was always on a collision course.

6. Crews had access to immediate cooperative radio communication with any aircraft they could see on the Cockpit Situational Display.

7. No secondary tasks (very low workload).

8. Crews could expect at least one conflict per scenario.

9. All aircraft were assumed to have similar equipage, although no Intruder aircraft ever used this equipage until contacted by the Ownship crew.

10. All aircraft shared a single frequency but there was only a small amount of extraneous "chatter" unrelated to potential conflicts with Ownship.

The effect of many of the above features was to assume highest quality surveillance and alerting information, extremely reliable and

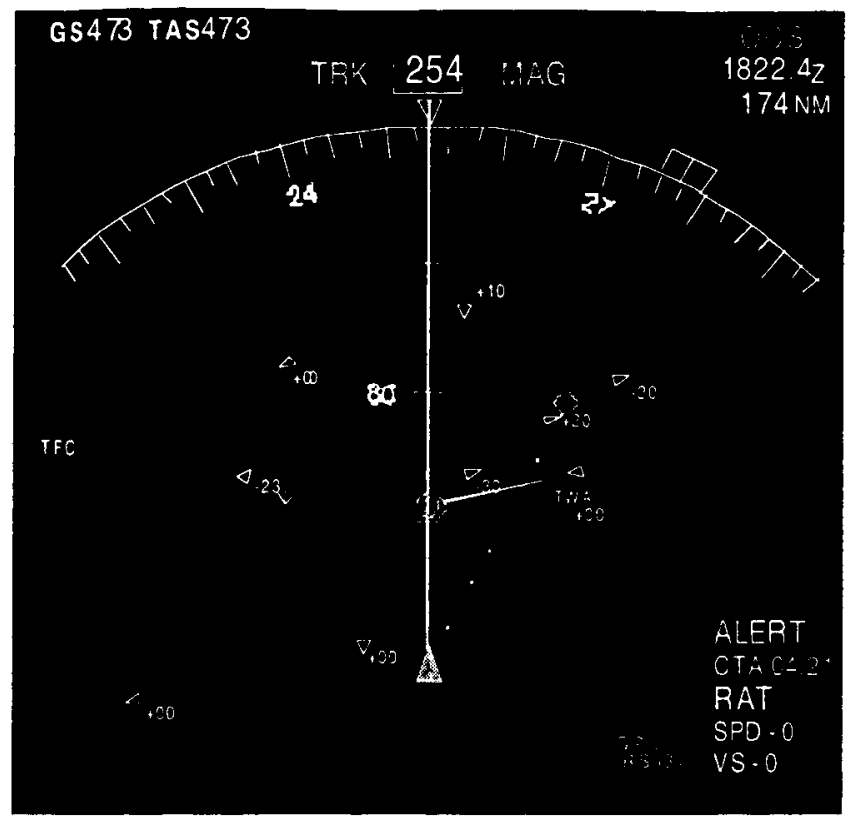

Figure 9. Using the RAT to find a clear path resolution to an $\mathrm{SA}_{3}$ alert. Blue is depicted as bold white.

easy flight deck to flight deck communications, very little dynamic traffic complexity, a low surprise factor to conflicts, and no distractions. However, there were also some aspects that may have made the task more difficult than might be expected in flight operations. Among these are the following:

1. No cardinal altitude rules were assumed, thus making head-on conflicts possible.

2. There was minimal experience with the system (about 2 hours of training).

All flight scenarios presented crews with one of two cockpit situational displays. These two displays, a Basic and Enhanced version described in the next section, relied upon a simulated ADS-B surveillance system. This simulated ADS-B system broadcasts information to, and receives information from, all aircraft within a $120 \mathrm{NM}$ surveillance range twice a second. The information being broadcast contained altitude, $x-y$ location, heading, ground speed, and aircraft ID. The crews were given an initial briefing in which they were told that all flights were either from JFK to SFO, or the SFO to JFK, and that all the scenarios took place in the Denver Center airspace between the Rock Springs VOR (OCS) and the Scott's Bluff VOR (BFF). At 
the beginning of each scenario they were given a specific initial position and flight path. During the scenario the crews were told that they could expect their CSD to alert them to a potential conflict, and that they would then have to resolve it safely. They were also informed that failure to resolve the conflict in a sufficiently timely manner could result in an ATC intervention canceling Free Flight and returning control to the air traffic controller. They were told that this intervention would only occur after a $\mathrm{SA}_{3}$ alert ('Alert zone contact') and only if they were not satisfactorily handling the conflict. Crews were told to assume that they could contact any aircraft that they could see on the CSD by simply addressing that aircraft on the radio, and that all aircraft would be tuned to the same frequency. Crews were told that all aircraft were equipped in a manner similar to themselves (i.e., with the same type of CSD and ADS-B transmitting and surveillance system).

\section{Dependent Measures}

Since the crews were instructed to stay within required separation standards ( $5 \mathrm{NM}$ lateral and $1000 \mathrm{ft}$ vertical), dichotomous classification into success and failure at that task is an obvious measure of interest. Unfortunately, as mentioned in the Introduction, this binary measure is relatively insensitive for most simulation studies, and indeed, minimal separation was never lost in any of the scenarios.

However, other dependent measures, specifically, minimum separation, response proactivity, and number of Ownship maneuvers, are still of interest. These were selected since 1) separation is a critical concept, 2) the display was designed to provide advanced alerts that allow proactive responding, and, 3) the RAT allowed evaluations of whether maneuvers would result in a clear path that required no further maneuvering. However, none of these variables is a simple measure of the quality of overall performance, so caution must be exercised in generalizing from these analyses (e.g., creating too much separation may lead to inefficient flight; responding too early may generate unneeded maneuvers; more and smaller maneuvers may be more adaptive in cases of higher uncertainty).

Minimum separation. Minimum co-altitude separation between Ownship and the Intruder, and between Ownship and the rest of the traffic (Context Traffic) were examined. Two other possible measures of separation, slant range separation, and vertical separation when aircraft were laterally within 5 NM of each other, were not used. Slant range was not used since vertical and lateral proximity are so unequally weighted when evaluating effective separation. The vertical separation measure was not used, since aircraft only infrequently came within $5 \mathrm{NM}$ laterally of each other.

Therefore the determination of minimum separation between the Intruder and Ownship was accomplished by calculating lateral separation at all moments that the two aircraft were not vertically separated, and then selecting the minimum of these data points. Instead of the instructed $1000 \mathrm{ft}$ vertical separation minimum, $900 \mathrm{ft}$ was used in the analysis to allow a suitable margin of error.

Minimum separation between Context Traffic and Ownship was determined using a two step process. First the minimum separation was calculated for each of the Context Traffic aircraft using the same process described earlier. Then the smallest of these minimums was used as the measure of the minimum separation of the Context Traffic from the Ownship.

Response Proactivity. This measure assessed the degree of proactive control by crews. To do this the maximum conflict probabilities between Ownship and the Intruder were examined. These conflict probabilities were the estimated probabilities of conflict if no maneuver was taken and were supplied by the alerting algorithm (see the previous section on 
Conflict Alerting). These probabilities are relatively proportional to the time remaining before a predicted conflict. As such, this measure reflects how close in time a conflict was allowed to approach before it began to be resolved (either by either the Intruder or the Ownship). In all of the analyses Response Proactivity will be plotted as the value of 1.0 minus the maximum conflict probability since this number more closely reflects proactivity (a larger number is more proactive).

It is very important to keep in mind that this measure is not a good absolute indicant of level of threat or danger. It is only one dimension of the two dimensions included in the overall conflict logic, excluding the dimension reflecting the amount of maneuvering that remains available.

Number of Ownship maneuvers. The mean number of discrete commanded changes to Ownship heading, altitude rate, and speed were examined in separate analyses. Commands were categorized as single discrete commands when separated by at least 20 seconds during which time no new commanded changes in these vehicle states occurred. For example, if commanded heading started to change, remained stable for 10 seconds, changed again, and then remained stable for 30 seconds, this would be considered a single heading command. Examining number of Ownship maneuvers is meaningful, since it indicates if the increased information and tools available in the Enhanced display led to more or less maneuvering.

\section{Method}

\section{Design}

The study employed a 2 (Display Mode) by 8 (Scenario) mixed factorial design. Display Mode was the between subjects factor with five Boeing 747-400 line crews from a major airline in each of the two between subjects groups. Scenario was the within subjects factor with all ten crews presented with the eight pre-programmed conflicts.

\section{Scenario Construction}

In each scenario, Ownship had an initial altitude of 33000 feet, and an initial ground speed of 473 knots. During each scenario the flight plan segment of Ownship included no turns, no altitude changes, and no speed changes. Each of the eight scenarios was constructed by randomly placing Context Traffic within several intersecting flight corridors that were located, in turn, within the relevant part of the Denver Center airspace. Each corridor was 25 to 30 miles wide and was located in the $29000 \mathrm{ft}$ to $37000 \mathrm{ft}$ range. Traffic could be traveling in either direction along the corridor, and had $1000 \mathrm{ft}$ vertical separation (e.g. 29000, 30000, .. 37000). Thus these scenarios reflected no cardinal altitude rules and reduced vertical separation minimums. Ground speeds ranging between 400 and 500 knots were randomly assigned to these aircraft, and 1-2 Context Aircraft changed altitude per scenario. All aircraft were assumed to be of similar type and equipage. A sufficient number of Context Traffic were generated so that between 6 and 10 of the Context Traffic were always in view on the traffic display during the course of each scenario. Scenarios varied in duration, with the shortest scenario being 12 minutes and the longest being 22 minutes. Table 3 lists the eight conflicts used in the study. These conflicts were generated by the deliberate placement of Intruders. The descriptions in Table 3 show the sequence of $\mathrm{SA}$ levels through $\mathrm{SA}_{3}$ if Ownship does not maneuver. Table 3 also shows which aircraft is presumed to have the right-of-way. The rightof-way "rules of the road" employed were taken from FAA FAR Part 91. These rules are:

1. In any head-on encounter both aircraft should maneuver to the right.

2. In any co-altitude non-head-on encounter the aircraft on the right has the right-ofway.

3. In any co-altitude overtake encounter the aircraft in the lead has the right-of-way. 
The FARs state no specific right-of-way rules for encounters during altitude changes, so no such rules were assumed or stated to the crews during their briefings. If the Ownship did not maneuver, the Context Traffic never generated a conflict with Ownship, Intruder, or each other.

\section{Task}

Crews were required to fly eight enroute scenario segments. They were informed that during these scenarios there would be no cardinal altitude rules, the vertical separation minimum would be 1000 feet (reduced from the standard $2000 \mathrm{ft}$ high altitude minimum), and the lateral separation minimum was the standard $5 \mathrm{NM}$. To accomplish this they were allowed to maneuver freely and did not have to seek the ATC's approval, although they were free to communicate with the ATC at any time. The role of the ATC and of the crews in the other aircraft was played by a single experimental confederate who was a former air traffic controller. Crews were also informed that all aircraft were assumed to share a single radio frequency and that they could communicate with any other aircraft by simply addressing it using its aircraft ID. They were also told not to assume that the ATC or any other aircraft could overhear such communications (i.e., if they wanted the ATC or any other aircraft to know something then they had to address the ATC or that aircraft directly). When experimental crews did communicate with other aircraft the experimental confederate would respond. Scenarios ended after the conflict with the designated Intruder was cleared.

\section{Procedure}

An initial briefing was held for each crew in which the experimenters described, 1) the task; 2) the FAA VFR "rules of the road" for conflict resolution; and 3 ) the display tools (if any). Following this, each crew received 1-2 hours of initial training in which they became familiar with the display and the display tools. The crews then flew the eight experimental scenarios, which took between 2 and 3 hours. Following this the crews were debriefed.

\section{Results}

Global Analysis: The minimum separation, response proactivity, and maneuvering data for Intruders were examined using a $2 \times 8$ (Display Mode by Scenario) mixed analysis of variance (ANOVA). The same analysis was conducted on the minimum separation data for the Context Traffic. The two levels of Display Mode were 1) Basic ( $\mathrm{SA}_{3}$ and TCAS II SA levels, and no tools) and 2) Enhanced ( $\mathrm{SA}_{1}$ - $\mathrm{SA}_{3}$ and TCAS II SA levels, predictor tool, and RAT). The eight levels of Scenario correspond to those listed in Table 3.

\section{Targeted Analysis: A more targeted ANOVA} was used to examine these same dependent variables in Scenarios 1-4, but only for the Intruder and Maneuver data. These scenarios are of special interest, because they reflect a factorial combination of three factors: Display Mode, Direction, and Range. Here, Direction refers to whether an Intruder approaches from the left or the right, and Range refers to

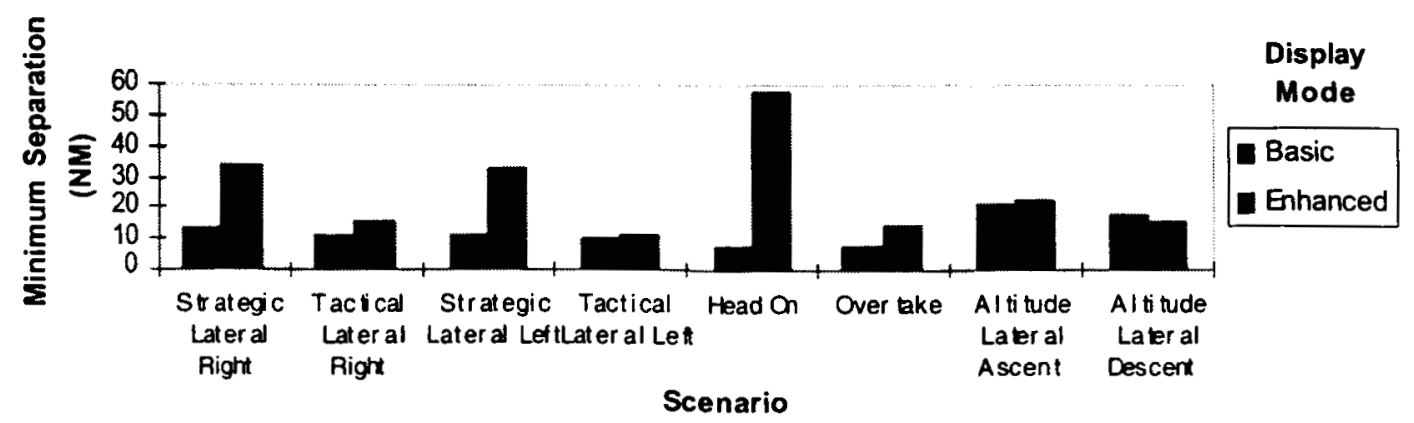

Figure 10. Mean minimum separation with Intruder versus Display Mode and Scenario. 
whether the Intruder was on a conflicting path at a Strategic or Tactical range. Therefore these data were analyzed using a $2 \times 2 \times 2$ mixed ANOVA. The particular value of this analysis is that it allows for a more direct evaluation of the roles of Display Mode and Range.

Performance data from one crew for one scenario (Scenario 2, Basic Display Mode) were accidentally not recorded, and for statistical analyses these data were replaced with data averaged over the other four crews in the Basic Display condition for Scenario 2.

\section{Intruder Data}

Minimum Separation: Figure 10 shows the mean minimum separations between Ownship and Intruder. The global ANOVA showed statistically significant main effects for Scenario $(F(7,56)=21.074, p<0.001)$ and Display Mode $(F(1,8)=19.422, p=0.002)$, and a significant Scenario by Display Mode interaction $(F(7,56)=2.907, p=0.012)$. Examination of the interaction shows that crews with the Enhanced display had larger minimal separations in the strategic lateral and head-on scenarios than did crews with the Basic display. The mean size of these separations looks large if one thinks of the separations as coming solely from co-altitude passing maneuvers. However, these separations often resulted from Ownship or the
Intruder changing altitude. When this occurred early, it could lead to large minimum separations (e.g., climbing 1000 feet when 50 miles from the Intruder yields a minimum separation of 50 miles).

The targeted analysis yielded no significant effects, although the effect of Range was marginally significant $(F(1,8)=4.213, p=$ 0.074).

\section{Response Proactivity: Figure 11 shows} response proactivity as a function of Scenario and Display Mode. The global analysis showed statistically significant main effects for Scenario $(F(7,56)=21.074, p<0.001)$ and Display Mode $(\mathrm{F}(1,8)=19.422, \mathrm{p}=0.002)$, and a significant Display Mode by Scenario interaction $(F(7,56)=2.907, p=0.012)$. Examination of the interaction shows that crews with the Enhanced display had more proactive (earlier) resolutions in the strategic lateral and the overtake scenarios than did crews with the Basic display.

The targeted analysis yielded significant main effects for Display Mode $(F(1,8)=16.649, p=$ $0.004)$ and Range $(F(1,8)=139.176, p<$ 0.001 ), and a marginally significant main effect for laterality $(F(1,8)=5.055, p=0.055)$. There was also a significant Display Mode by Range interaction $(F(1,8)=10.563, p=0.012)$. These effects showed that resolutions were

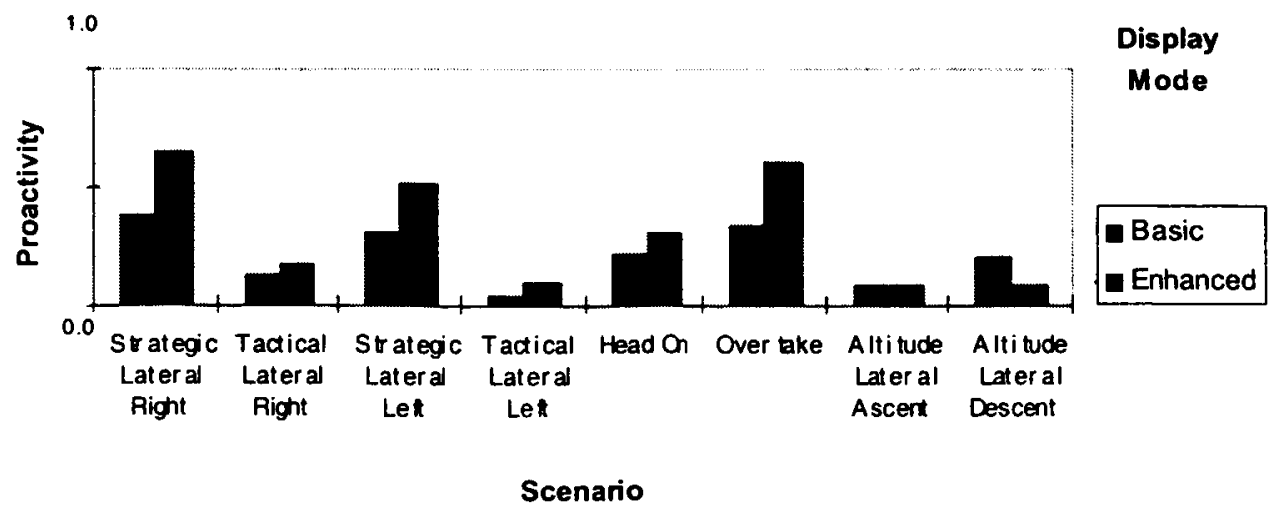

Figure 11. Response Proactivity to Intruder versus Display Mode and Scenario. 
more proactive when the crews had an Enhanced Display, when the conflicts were Strategic, and perhaps when the conflicts occurred on the right. The interaction showed that the effect of the Enhanced display was larger when the conflict was Strategic. That is, the Enhanced display led to a greater increase in response proactivity when there were Strategic conflicts than when there were Tactical conflicts.

Discussion: The global analysis showed that when Ownship had an Enhanced display the resolutions in the overtake and the two strategic lateral scenarios were more proactive. This is not surprising since the temporal differences between the $\mathrm{SA}_{1}$ and the $\mathrm{SA}_{3}$ were greatest in these scenarios. That is, there was much more opportunity for proactive responding in these scenarios.

On the other hand, the two tactical and two altitude scenarios allowed little time between these two events (In the altitude scenarios Ownship never needed to maneuver. Instead, the Intruder was scripted to always maneuver at a specific location to avoid a conflict).

As would be expected, the targeted analysis also showed more proactive responding with Enhanced displays and with Strategic conflicts. Additionally, it showed that the size of this Display Mode effect depended substantially on whether or not there was a long enough range (i.e., a Strategic range). It is not surprising that the advance alerting and tools are less useful when conflicts occur suddenly and late.

The global analysis showed that use of the Enhanced display in the head-on conflict, and in the two strategic lateral encounters, also led to increased minimum separations.

Discounting the two altitude encounters (which did not require a resolution), these conflicts were present at the greatest distances from Ownship. This importance of range was furthered supported by the marginally significant effect of Range on minimum separation in the target analysis.

Finally, it is interesting to note that allowing more time to detect a conflict resulted in more proactive responding for crews using either the Basic or the Enhanced display. Thus, crews responded earlier with and without the display enhancements when allowed to view the conflict developing over a longer period of time. However, care must be taken in interpreting this result. As noted earlier, every scenario contained a conflict and the crews were free to focus almost all of their attention on finding it.

\section{Context Traffic Data}

Minimum Separation: A global analysis of minimum separation from the Context (nonIntruder) Traffic was conducted to determine if the Display Mode manipulation led to any differences in minimum separation with the Context Traffic. Initial examination of these data showed two extreme outliers which strongly skewed the distributions and means. Although an ANOVA yielded equivalent statistical outcomes with and without these outliers, they were removed from the data to obtain a better estimate of the mean performance. Figure 12 shows the average minimum separation between Ownship and Context Traffic as a function of Display Mode and Scenario. The main effect of Scenario was statistically significant $(F(7,56)=13.265$, $p<0.001$ ). This effect was probably due to the idiosyncratic nature of the various scenarios, since no particular care was taken to equalize separation from Context Traffic across scenarios with respect to initial trajectories, nor with respect to some nominal trajectory resolutions. There were no statistically significant effects of Display Mode or Display Mode by Scenario interaction ( $\mathrm{F}<$ 1.00) on minimum separation from Context Traffic. 


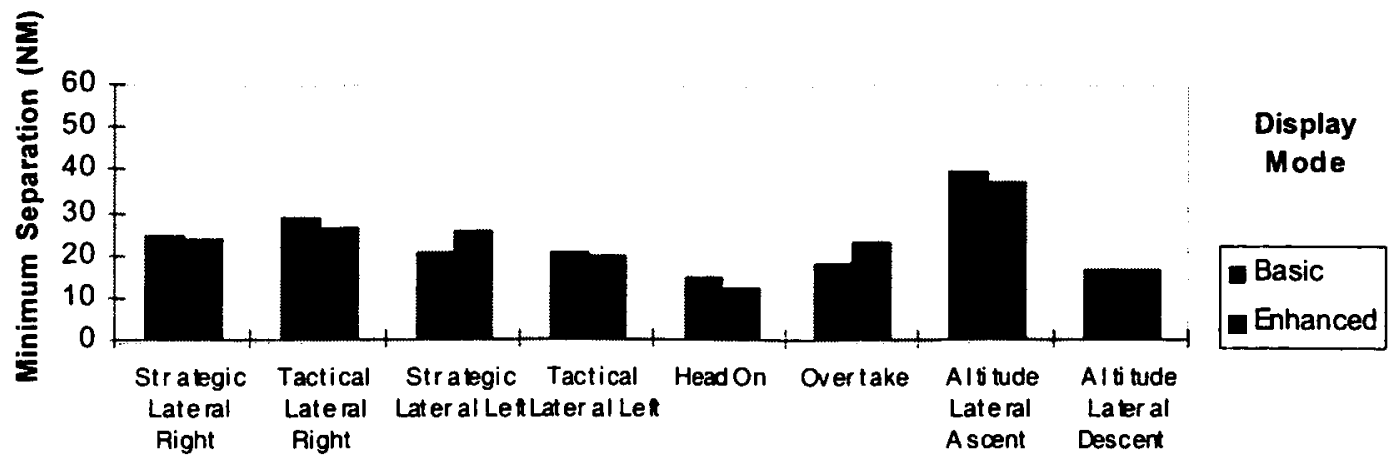

Scenario

Figure 12. Adjusted mean minimum separation with Context Traffic versus Display Mode and Scenario.

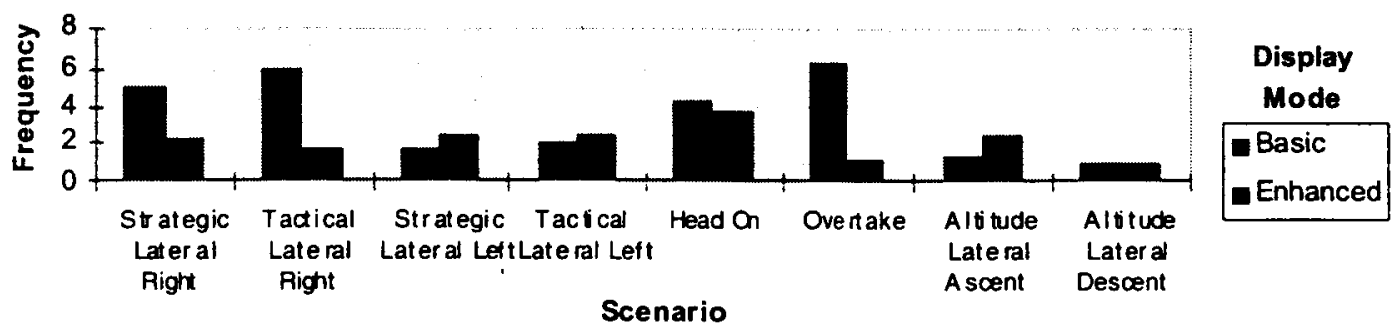

Figure 13. Mean frequency of Ownship heading maneuvers versus Display Mode and Scenario.

Discussion: There is no evidence that the display led to a change in minimum separation from Context Traffic.

\section{Maneuver Data}

Heading and altitude maneuvers were examined using the global ANOVA and the targeted ANOVA. Speed maneuvers were not examined since there were almost no changes to speed, averaging less than 0.2 per scenario. This was probably due to the long time lag involved in changing speed, and the relatively small amount by which a transport aircraft's speed can be changed in the enroute environment.

Heading Maneuver Analysis: There were, on average, 2.8 heading changes per scenario. Figure 14 shows the mean number of heading changes as a function of Scenario and Display Mode. The global analysis reveals a statistically significant main effect for Scenario $(F(1,8)=2.221, p=0.046)$ and Scenario by
Display Mode interaction $(F(7,56)=2.436$, $\mathrm{p}=0.03$ ). In particular, Figure 14 shows that the Enhanced display led to a reduced number of heading maneuvers in the strategic and tactical right lateral scenarios and in the overtake scenario. The lack of any effect of Display Mode in the left lateral scenarios, and in the altitude change scenarios, is not surprising. The rules of the road specify that Ownship is not required to maneuver in the left lateral scenarios. Similarly, in the Altitude Lateral scenarios, when the Ownship crews contacted the crews of the Intruder aircraft, the Intruders agreed to level off 2000 feet above or below the Ownship, and again there was less need to maneuver. In these scenarios the Enhanced Display may show little or no impact, because there was little need for the Ownship to maneuver.

While the global analysis of heading maneuvers suggests roles for both laterality (whether the Intruder approaches from the left 


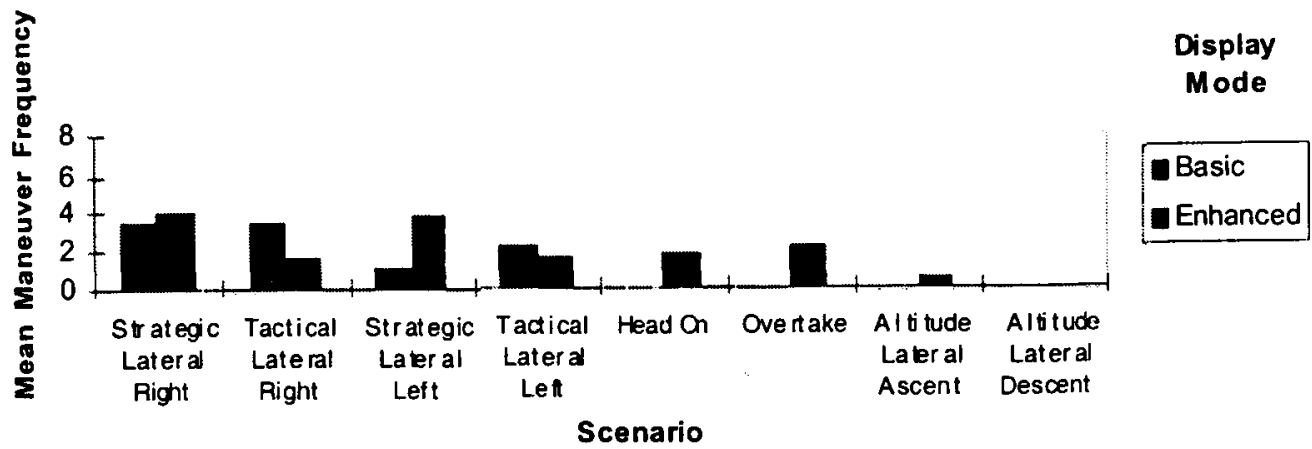

Figure 14. Mean frequency of Ownship altitude maneuvers versus Display Mode and Scenario.

or right) and Display Mode, the targeted analysis did not generate any statistically significant effects.

Altitude Maneuver Analysis: There were an average of 3.8 changes to altitude rate per scenario. While this appears to indicate that altitude maneuvers were quite frequent, closer examination of these data revealed that the majority of changes to altitude rate were due to two crews, one in each of the two Display Mode conditions. Both of these crews averaged about 12.5 altitude changes per scenario. During debriefing, it became apparent that they almost always changed altitude to resolve conflicts, because they determined that they had been placed well below the cruising altitude that offered optimum fuel efficiency. Thus, they always climbed to avoid any conflicts. When these crews were eliminated from the analysis the mean number of altitude change inputs dropped from 3.8 to 1.6 per scenario. Figure 14 shows the mean number of altitude rate changes as a function of Scenario and Display Mode for the remaining four crews.

The global analysis of these data reflect a statistically significant main effect for Scenario $(F(1,8)=2.569, p=0.027)$, but no significant effects involving Display Mode. No statistically significant effects were found in the targeted analysis. While it appears that the effects of Scenario are due to an increased likelihood of making an altitude maneuver during horizontal lateral encounters, the reasons for this effect are not obvious.

\section{Discussion}

Display Mode appears to have only had an effect on the use of heading maneuvers, with crews apparently using fewer heading maneuvers when they had an Enhanced display.

\section{Crew Debriefing}

All crews were debriefed following the completion of the eight scenarios. This allowed for a spontaneous exchange of information.

The debriefing provided much valuable, but not easily quantifiable, information about the strengths and weaknesses of the display. In general, the crews in both the Basic and the Enhanced Display conditions found their displays adequate to do their tasks, and they were generally enthusiastic (with qualifications) about using these displays for Free Flight. The following five categories reflect many of the comments that the authors feel provided the most valuable guidance for the present, and future, display designs.

Clutter and Filtering: Clutter, and its associated impacts on detection and salience, emerged as an important issue in the debriefings. In particular, both data blocks and the predictors were noted as potential problems. Several pilots noted that the altitude and call sign text in the data blocks could be a problem. Some pilots liked flying with data blocks fully enabled (i.e., with call signs), but several pilots wanted call signs to be 
individually selectable. Similarly, several pilots noted that having all predictors on at once led to a clutter problem, and saw individual selectability as a solution to the problem.

Several pilots suggested dealing with clutter by filtering which aircraft were displayed on the basis of relevance. For example, it was suggested that altitude filtering could be implemented on the basis of proximity to Ownship altitude (e.g., allowing a pilot to select only aircraft within $4000 \mathrm{ft}$ of Ownship). Another suggestion was to allow the crews to select just the aircraft below or above Ownship. Other suggestions were to filter out all aircraft except for those that were laterally converging on Ownship path, and/or those that were vertically converging on Ownship altitude. However, one crew also noted that people might forget that such selectable filters were enabled, thereby believing they were seeing the whole picture. This crew suggested that any such selectable filter only be enabled for a specified period of time, and then automatically revert to an unfiltered status. Finally, two crews suggested that aircraft based filtering could be accomplished without fully eliminating aircraft from a display. They suggested that it would be possible to differentially emphasize information on the basis of its probable relevance, such as by linking brightness to relevance.

Tools: Since the tools were only made available to the crews using the Enhanced Display, almost all relevant comments came from these crews. Several of these crews said that they would like enhancements to the RAT that allow the evaluation of relative efficiency of maneuvers. Most crews noted that they made great use of the predictor tool, and two crews indicated they wanted it to remain on (not be cleared) after an $\mathrm{SA}_{3}$ alert. Two crews also liked to leave the predictor tool on and set at ' 0 ' so that a five mile diameter ring was always around all aircraft.
Two crews noted problems with the RAT. One crew said that they tried to use the RAT initially, but after it twice required excessive turns they stopped using it. A second crew did not like that a conflict would sometimes reappear after a safe heading was found and the heading change was made using the heading selector on the mode control panel. The problem probably arose when they first made a turn that the RAT indicated would result in a clear path. This crew (and maybe others) did not fully understand that when they turned the RAT off, the system would once again begin evaluating the present course of the Ownship based on its velocity vector. If the velocity vector of the aircraft was not yet turned to a heading sufficiently clear of the conflict, the SA level symbology would return and remain on until the turn had aimed the velocity vector sufficiently clear of the conflict. These pilots' comments suggest that it would be better to have alerts and SA levels that take into account the projected route of the Ownship (based on initiations of predetermined maneuvers) rather than make SA levels simply dependent upon the Ownship's instantaneous velocity vector.

The Value of Early Information: Many crews' comments reflected the value of information at an extended range. Several pilots said that information on aircraft beyond $120 \mathrm{NM}$ would be useful. Specifically, they thought that this would aid in planning (especially for altitude maneuvers) and would reduce the size of needed maneuvers. One crew even thought that a $640 \mathrm{NM}$ range would be useful in oceanic flight. Only one crew (in the Basic Display condition) indicated that there was no payoff for maneuvering early, and this crew stated that they did not feel that it was their task to avoid an alert zone contact. Another crew in the Basic Display condition indirectly highlighted the importance of early information when they stated that the CTA (estimated time to closest approach), which did not appear until the $\mathrm{SA}_{3}$ alert, determined their choice of maneuvers. 
Information About Intent: Adding more specific intent information to the display was another concern of several pilots. In addition to the basic velocity vector information that was being used to project intent on the Enhanced display, the crews obtained intent information using radio communications. For example, critical intent information was only obtainable over the radio in the two scenarios where the intruding aircraft was descending or ascending to altitudes $2000 \mathrm{ft}$ above or below Ownship (and thus posed no real threat). In other scenarios negotiations with the Intruder, or with other Context Traffic that were simply going to come close to Ownship, included specifications or agreements concerning intent (i.e., "I know you are there and will maintain my altitude and heading"). In light of this, one crew noted that display of digitally (nonvoice) exchanged intent information is desirable when flying over non-English speaking countries. Among the enhancements to displayed intent information suggested by one or more crews were: 1) intended final altitude when an aircraft was changing altitude; 2) intended course change (prior to course change); and 3) a trend vector on other aircraft in parallel flight and near minimum separation. Finally, one crew noted that, for the automated exchanges, it would be important to know who was sending and receiving intent information.

Miscellaneous: For both display conditions there was a mixture of preferences expressed for relative or absolute altitude, with the often stated preference for selectable modes. Some crews also thought that turn rate and turn direction would be valuable additions to the display. Several crews in the basic display condition also expressed the desire for enhancements that would provide more temporally advanced conflict alerting, and/or predictive tools, with these enhancements being generally similar (and sometimes identical) to those provided with the Enhanced Display.

\section{General Discussion}

The results of the simulation have tended to validate the approach used in the design of the prototype CSD. Specifically, relative to the Basic display, the Enhanced display allowed more proactive responding by the crews. The Enhanced display was especially effective at this in scenarios where the crew were able to see the conflict developing over a longer interval. Furthermore, in scenarios where the initial distance between Ownship and Intruder was large, crews with the Enhanced display generated larger minimum separations. These results may be accounted for by the simple hypothesis that advanced information and good resolution tools make early resolutions possible.

Furthermore, the data show no inherent tendency on the part of the crews to maneuver more often when given these enhancements, but instead shows an opposite trend for heading maneuvers. While there are other possibilities, this may suggest that the RAT allowed crews to more effectively plan lateral route adjustments. In contrast, the lack of any effect of Display Mode on altitude adjustments suggests that the RAT may have been a differentially effective planning tool across types of maneuvers. This would not be surprising since 1) the RAT did not provide an easy to use pictorial depiction of the proposed altitude maneuver (e.g. a profile view), and 2) the RAT evaluated the a change to altitude rate, but did not include leveling off at a specific altitude that is needed for a complete specification of the maneuver. Further research and development on the RAT is needed to evaluate and/or improve the utility of the display for altitude maneuver planning.

However, the evaluation of this display has been done under very idealistic assumptions (already enumerated) that will rarely hold in a real enroute environment. For example, in this study the crews focused their attention almost entirely upon the CSD, and it provided nearly perfect conflict alerting. The value of the 
alerting symbology must be assessed under conditions where there is incomplete and/or noisy surveillance information, and where conflicts are more rare. Also, the display must be evaluated in situations where the crew has other duties that take attention away from the CSD.

The value of the individual design elements must also be assessed. The present CSD design incorporated a number of features (e.g., general traffic depiction, alerting symbology, RAT, and predictor tool). The relative importance of these individual features needs to be examined.

The debriefings of the crews also provided some very good information that should be useful in directing future research and development on new display features. For example, clutter remains a problem and future work must address this. The present simulation was limited to a maximum of 10 aircraft on the display at one time, distributed across 9 adjacent flight levels, and with no extraneous speed and heading changes. Some informal examinations, by the present authors, of the air traffic density in the Denver Center showed that it could rise to 20 , and sometimes 30 aircraft within 3 adjacent flight levels. Therefore some method of filtering or prioritizing what aircraft or symbology to display will be necessary. The data tags are a clearly a major source of clutter and methods for reducing this must be addressed. Totally removing them without providing some other form of altitude information is not an option. Methods of filtering out aircraft, or aircraft tag information, based on various measures of proximity or relevance was a primary solution suggested by the pilots. Another potential solution entails the use of alternative spatial formats (e.g., 3-D or multiple 2-D views) that more effectively/efficiently display altitude information. Another potentially effective method of dealing with clutter is to draw attention to important information by increasing the salience of symbols and text associated with that information, while decreasing the salience of the symbols associated with less important information (e.g., manipulation of brightness).

Despite the clutter problem, the display of other types of information, primarily regarding intent, must also be considered and evaluated. Pilots suggested displaying information about how other aircraft are maneuvering, and providing advanced information indicating intent to maneuver. Furthermore, it is not clear if a $120 \mathrm{NM}$ range is too little or too much (although no pilots indicated that it was too little).

Finally, there was near unanimous agreement that predictors were desirable. However, there is still a need to present information that effectively shows both the predictions and the certainty of the predictions. The SA levels in the alerting system were designed to do this, but the extrapolations generated by the predictor tool were not. Furthermore, it is not clear in either case that the pilots were actually utilizing this information. A more controlled study is necessary to evaluate this.

In conclusion, the comments and the performance data from this simulation are encouraging. They both show acceptance of the display and a moderate to substantial confidence among the pilots that they could, and would like to, do this task with this type of display. Further development and more controlled evaluations will be necessary, however, before the desired functionality of the CSD for any specific Free Flight implementation can be established. 
Table 3. Descriptions of the conflicts in each of the eight scenarios.

\begin{tabular}{|c|c|}
\hline Scenario Name & Scenario Description \\
\hline $\begin{array}{l}\text { Right Strategic } \\
\text { Lateral }\end{array}$ & $\begin{array}{l}\text { Intruder aircraft (ground speed = } 473 \text { knots) approaching on a collision } \\
\text { course from the right at beginning of scenario, but too distant to } \\
\text { immediately trigger any } \mathrm{SA} \text { level. } \mathrm{An}_{\mathrm{SA}} \mathrm{SA}_{1} \text { is triggered } 8.2 \text { minutes into the } \\
\text { scenario, and this is followed by an } \mathrm{SA}_{2} 2.3 \text { min later, and then by an } \mathrm{SA}_{3} \\
2.2 \text { minutes after that. In this scenario the Intruder has the right of way. }\end{array}$ \\
\hline $\begin{array}{l}\text { Right Tactical } \\
\text { Lateral }\end{array}$ & $\begin{array}{l}\text { Intruder aircraft (ground speed }=457 \text { knots) to the right of Ownship and } \\
\text { on a parallel course at beginning of scenario. Intruder turns onto collision } \\
\text { course } 9 \text { minutes into the scenario. This triggers an } \mathrm{SA}_{1} \text { and then } \\
\text { transitions through an } \mathrm{SA}_{2} \text { and an } \mathrm{SA}_{3} \text { (alert zone contact) within the next } \\
10 \text { seconds. In this scenario the Intruder has the right of way. }\end{array}$ \\
\hline $\begin{array}{l}\text { Left Strategic } \\
\text { Lateral }\end{array}$ & $\begin{array}{l}\text { Intruder aircraft (ground speed }=473 \text { knots) approaching on a collision } \\
\text { course from the left at beginning of scenario, but too distant to immediately } \\
\text { trigger any advanced } \mathrm{SA} \text { level. An } \mathrm{SA}_{1} \text { is triggered } 0.7 \text { minutes into the } \\
\text { scenario, and is followed by an } \mathrm{SA}_{2} 2.7 \text { min later, and then by an } \mathrm{SA}_{3} 3.3 \\
\text { min after that. In this scenario Ownship has the right of way. }\end{array}$ \\
\hline $\begin{array}{l}\text { Left Tactical } \\
\text { Lateral }\end{array}$ & $\begin{array}{l}\text { Intruder aircraft (ground speed }=473 \text { knots) to the left of Ownship and on } \\
\text { a parallel course at beginning of scenario. Intruder turns onto collision } \\
\text { course } 7.3 \text { minutes into the scenario. This triggers an } \mathrm{SA}_{1} \text { and then } \\
\text { transitions through and } \mathrm{SA}_{2} \text { and } \mathrm{SA}_{3} \text { (alert zone contact) within the next } 15 \\
\text { seconds. In this scenario Ownship has the right of way. }\end{array}$ \\
\hline Head-on & $\begin{array}{l}\text { Intruder aircraft (ground speed }=473 \text { knots) on a head-on collision course } \\
\text { at the beginning of the scenario, but is outside of surveillance range. The } \\
\text { Intruder enters the surveillance range } 8.2 \text { minutes into the scenario at which } \\
\text { point it immediately triggers an } \mathrm{SA}_{1} \text { which transitions to an } \mathrm{SA}_{2} \text { alert } 20 \\
\text { seconds after that. The Intruder finally triggers an } \mathrm{SA}_{3} \text { (alert zone contact) } \\
2.3 \text { minutes following this. Right of way rules indicate that both the } \\
\text { Intruder and the Ownship should maneuver to the right. }\end{array}$ \\
\hline Overtake & $\begin{array}{l}\text { Ownship overtaking Intruder aircraft (ground speed }=403 \text { knots) from } \\
\text { directly behind, and triggers an } \mathrm{SA}_{1} 2.5 \text { minutes into the scenario, which is } \\
\text { followed by an } \mathrm{SA}_{2} 6 \text { minutes later, and then an } \mathrm{SA}_{3} \text { (alert zone contact) } 2.5 \\
\text { minutes after the } \mathrm{SA}_{2} \text {. In this scenario Ownship has the right of way. }\end{array}$ \\
\hline Lateral Descent & $\begin{array}{l}\text { Intruder aircraft (ground speed }=445 \text { knots) } 4000 \text { feet above and to the } \\
\text { left of Ownship, and on a path that will pass directly above Ownship. } \\
\text { Intruder begins descent toward Ownship } 7.3 \text { minutes into the scenario, } \\
\text { triggering an immediate triggering an immediate } \mathrm{SA}_{1} \text {, which progresses } \\
\text { through an } \mathrm{SA}_{2} \text { and then an } \mathrm{SA}_{3} \text { (alert zone contact) within about } 8 \\
\text { seconds. If contacted, the pseudo-pilot controlling the Intruder informs the } \\
\text { Ownship crew of his intention to level off } 2000 \text { above below Ownship. This } \\
\text { is accomplished } 2.5 \text { minutes later eliminating the } \mathrm{SA}_{3} \text { alert. }\end{array}$ \\
\hline Lateral Ascent & $\begin{array}{l}\text { Intruder aircraft (ground speed }=510 \text { knots) is initially out of surveillance } \\
\text { range. When Intruder appears, } 2 \text { minutes into the scenario, it is } 4000 \text { feet } \\
\text { below and to the right of Ownship, and on a path that will pass directly } \\
\text { below Ownship. Intruder begins ascent toward Ownship } 2.5 \text { minutes after it } \\
\text { comes within surveillance range, triggering an immediate } \mathrm{SA}_{1} \text {, which } \\
\text { progresses through an } \mathrm{SA}_{2} \text { and then an } \mathrm{SA}_{3} \text { (alert zone contact) within } \\
\text { about } 5 \text { seconds. If contacted, the pseudo-pilot controlling the Intruder } \\
\text { informs the Ownship crew of his intention to level off } 2000 \text { feet below } \\
\text { Ownship. This is accomplished } 2.25 \text { minutes later eliminating the } \mathrm{SA}_{3} \text { alert. }\end{array}$ \\
\hline
\end{tabular}




\section{References}

1. RTCA Task Force 3 (October, 1995). Final Report of RTCA Task Force 3: Free Flight Implementation, RTCA Inc., Washington DC.

2. Johnson, W. W. (1986). Studies in motion extrapolation. Unpublished doctoral dissertation, The Ohio State University, Columbus, Ohio.

3. Yang, L. and Kuchar, J. (1997). Prototype conflict alerting logic for free flight. In the Proceedings of the $35^{\text {th }}$ Aerospace Sciences Meeting, Reno, NV.

4. Paielli, R. and Erzberger, H. (1996). Conflict probability estimation for free flight. AIAA Journal of Guidance, Control, and Dynamics.
5. Aerospace Recommended Practice 4102/4 (1988, July). Flight deck alerting system (FAS). Warrendale, PA: Society for Automotive Engineers.

6. Shiner, R. J. and Sullivan, B. T. (1992). Man-Vehicle Systems Research Facility Design and operating characteristics. AIAA/AHS Flight Simulation Technologies Conference, Hilton Head Island, SC, Aug. 24-26, 1992, Technical Papers (A92-52426 22-09). Washington, American Institute of Aeronautics and Astronautics, p. 296-301. 


\begin{tabular}{|c|c|c|c|c|}
\hline \multicolumn{2}{|c|}{ Report Documentation Page } & \multicolumn{3}{|c|}{$\begin{array}{c}\text { Form Approved } \\
\text { OMB No. 0704-0188 }\end{array}$} \\
\hline \multicolumn{5}{|c|}{ 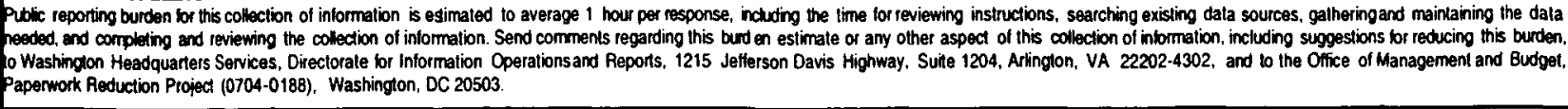 } \\
\hline 1. AGENCY USE ONLY (Leave blank) & \multicolumn{2}{|c|}{$\begin{array}{l}\text { 2. REPORT DATE } \\
\text { September } 2003\end{array}$} & \multicolumn{2}{|c|}{$\begin{array}{l}\text { 3. REPORT TYPE AND DATES COVERED } \\
\text { Technical Memorandum }\end{array}$} \\
\hline \multicolumn{3}{|c|}{$\begin{array}{l}\text { 4. TITLE AND SUBTITLE } \\
\text { Development and Demonstration of a Prototype Free Flight } \\
\text { Cockpit Display of Traffic Information }\end{array}$} & \multirow{2}{*}{\multicolumn{2}{|c|}{$\begin{array}{l}\text { 5. FUNDING NUMBERS } \\
727-05\end{array}$}} \\
\hline \multicolumn{3}{|c|}{$\begin{array}{l}\text { 6. AUTHOR(S) } \\
\text { Walter W. Johnson, Vernol Battiste, Susanne Delzell*, Sheila } \\
\text { Holland*, Sean Belcher", and Kevin Jordan* }\end{array}$} & & \\
\hline \multicolumn{3}{|c|}{$\begin{array}{l}\text { 7. PERFORMING ORGANIZATION NAME(S) AND ADDRESS(ES) } \\
\text { NASA Ames Research Center } \\
\text { Moffett Field, California } 94035-1000 \\
\text { *San Jose State University Foundation, San Jose, California }\end{array}$} & \multicolumn{2}{|c|}{$\begin{array}{l}\text { 8. PERFORMING ORGANIATION } \\
\text { REPORT NUMBER } \\
\text { IH-042 }\end{array}$} \\
\hline \multicolumn{3}{|c|}{$\begin{array}{l}\text { 9. SPONSORING/MONITORING AGENCY NAME(S) AND ADDRESS(ES) } \\
\text { National Aeronautics and Space Administration }\end{array}$} & \multicolumn{2}{|c|}{$\begin{array}{l}\text { 10. SPONSORING/MONITORING } \\
\text { AGENCY REPORT NUMBER } \\
\text { NASA/TM-2003-212273 }\end{array}$} \\
\hline \multicolumn{5}{|c|}{$\begin{array}{l}\text { 11. SUPPLEMENTARY NOTES } \\
\text { Point of Contact: Walter W. Johnson, M/S 262-2, Ames Research Center, Moffett Field, CA } 94035 \\
\qquad(650) 604-3667\end{array}$} \\
\hline \multicolumn{3}{|c|}{$\begin{array}{l}\text { 12A. DISTRIBUTIONAVAILABILITY STATEMENT } \\
\text { Subject Category: 54-03 Distribution: Public } \\
\text { Availability: NASA CASI (301) 621-0390 }\end{array}$} & \multicolumn{2}{|c|}{ 12B. DISTRIBUTION CODE } \\
\hline \multicolumn{5}{|c|}{$\begin{array}{l}\text { 13. ABSTRACT (Maximum } 200 \text { words) } \\
\text { Two versions of a prototype Free Flight cockpit situational display (Basic and Enhanced) were } \\
\text { examined in a simulation at the NASA Ames Research Center. Both displays presented a display of } \\
\text { traffic out to a range of } 120 \mathrm{NM} \text {, and an alert when the automation detected a substantial danger of } \\
\text { losing separation with another aircraft. The task for the crews was to detect and resolve threats to } \\
\text { separation posed by intruder aircraft. An Enhanced version of the display was also examined. It } \\
\text { incorporated two additional conflict alerting levels and tools to aid in trajectory prediction and path } \\
\text { planning. Ten crews from a major airline participated in the study. Performance analyses and pilot } \\
\text { debriefings showed that the Enhanced display was preferred, and that minimal separation between the } \\
\text { intruder and the ownship was larger with the Enhanced display. In addition, the additional } \\
\text { information on the Enhanced display did not lead crews to engage in more maneuvering. Instead an } \\
\text { opposite trend was indicated. Finally, crews using the Enhanced display responded more proactively, } \\
\text { tending to resolve alerts earlier. }\end{array}$} \\
\hline \multirow{2}{*}{\multicolumn{4}{|c|}{$\begin{array}{l}\text { 14. SUBJECT TERMS } \\
\text { Free flight, CDTI, Conflict detection, Conflict resolution }\end{array}$}} & $\begin{array}{l}\text { 15. NUMBER OF PAGES } \\
28 \\
\end{array}$ \\
\hline & & & & 16. PRICE CODE \\
\hline $\begin{array}{l}\text { 17. SECURITY CLASSIFICATION } \\
\text { OF REPORT } \\
\text { Unclassified }\end{array}$ & $\begin{array}{l}\text { 18. SECURITY CLASSIFICATION } \\
\text { OF THIS PAGE } \\
\text { Unclassified }\end{array}$ & $\begin{array}{l}\text { 19. SECURITY C } \\
\text { OF ABSTRA } \\
\text { Unclassifiec }\end{array}$ & $\begin{array}{l}\text { LASSIFICATION } \\
\text { CT } \\
\text { d }\end{array}$ & $\begin{array}{l}\text { 20. LIMITATION OF ABSTRACT } \\
\text { Unlimited }\end{array}$ \\
\hline
\end{tabular}

